\title{
Determination of Aluminum(III) in Crystallized Fruit Samples Using a Multicommutated Flow System
}

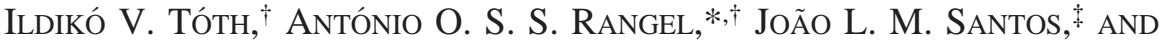 \\ José L. F. C. LIMA \\ Escola Superior de Biotecnologia, Universidade Católica Portuguesa, \\ Rua Dr. António Bernardino de Almeida, 4200-072 Porto, Portugal, and REQUIMTE/Faculdade de \\ Farmácia, Universidade do Porto, Rua Aníbal Cunha 164, 4050-047 Porto, Portugal
}

\begin{abstract}
A multicommutated flow system was developed for the determination of aluminum in crystallized fruit samples. Spectrophotometric determination is based on the reaction of aluminum with chrome azurol S. The binary sampling technique was implemented to improve mixing conditions and to minimize reagent consumption. Three different working zones were established $(0.5-5.0,5.0-25.0$, and $10.0-100 \mathrm{ppm}$ ) using the zone sampling approach, allowing us to adapt the extent of the in-line dilution. The influence of the chemical and physical parameters on the performance of the system was studied. Detection limits of $0.1,0.6$, and $0.8 \mathrm{ppm}$ were obtained for the lowest, the medium, and the highest dispersion system, respectively. The procedure was applied to the determination of aluminum in crystallized fruit extracts. The results were in agreement with those obtained by the reference flame atomic absorption procedure at a 95\% confidence level. Repeatability (RSD) was better than $2.4 \%$ in all of the three application zones.
\end{abstract}

KEYWORDS: Multicommutation; zone sampling; aluminum(III); crystallized fruits; spectrophotometry

\section{INTRODUCTION}

Determination and speciation of aluminum have received an increased attention in recent decades due to its recognized toxicity and its increasing availability in the environment. Aluminum is widespread in the environment and occurs naturally as part of the food and water supply. It is also introduced into foods and water through processing practices including the use of aluminum-containing additives. There is an increased concern of aluminum intake due to its possible role in the development or in the acceleration of the onset of Alzheimer's disease (1). Aluminum intake from foods, particularly those containing aluminum compounds used as food additives, represents the major route to aluminum exposure for the general public (2). Within the instrumental methods, electrothermal atomic absorption spectrometry and ICP AES are possible choices for the determination of the analyte in trace levels. However, these methods have a limited response range, which is a noteworthy weakness when dealing with samples of assorted concentration values, and relatively high costs per determination, leaving the molecular spectrophotometric methods still being popular.

A wide range of automated analytical systems was developed to monitor this analyte in water samples based on spectrophotometric or fluorimetric detection (3-7). The application to food

* To whom correspondence should be addressed. Tel: +351225580064 Fax: +351 225090351. E-mail: rangel@esb.ucp.pt.

Universidade Católica Portuguesa.

$\doteqdot$ Universidade do Porto. samples is far more limited. Various organic reagents have been used for the spectrophotometric determination (8) (pyrochatecol violet, eriochrome cianide R, CAS, pyrogallol, Aluminon, arsezano-III, etc.). For the development of automated methods, the use of CAS represents some advantages over the other options $(6,7,9)$. These advantages include rapid color development, use at room temperature, and simple experimental procedure. However, Fe(III) also reacts with CAS forming a complex that has an absorption maximum close to the one formed with aluminum. The interference of $\mathrm{Fe}$ (III) could be avoided by the use of an adequate reducing agent, like ascorbic acid. The spectrophotometric linear response range in the case of CAS can be limited by the intrinsic absorbance of the reagent at the monitoring wavelength $(545 \mathrm{~nm})$; therefore, the use of an in-line dilution system has to be considered to match the sample concentrations to the linear response range of the system.

MC (10) is a fairly recent flow analysis technique, characterized by the use of individual commutation devices. The manifold is usually constituted by a set of solenoid valves. These valves define the analytical path and the volume of the moving solutions and reaction zone formation just by a precise timebased control of their switching position. This method features both the strong points of SIA (11) such as minimization of solutions consumption and the use as multivalent systems (1214) and those of FIA (15) like efficient sample/reagents mixing. In $\mathrm{MC}$, the overlapping of the reagent and sample plugs can be maximized by implementing the binary sampling (tandem streams) mode, where a number of aliquots of different miscible 
solutions are introduced by rapidly and sequentially alternating between the distinct switching positions of the computercontrolled valves. The established stream is then composed of a set of neighboring solution slugs that undergo fast mixing while being transported through the analytical system. Kronka and Reis (16) developed a multicommutated system with binary sampling for the simultaneous determination of aluminum and iron based on spectrophotometric detection. The system was capable for the determination of aluminum in plant digests up to $15 \mathrm{ppm}$ using a relatively high volume flow cell $(180 \mu \mathrm{L})$.

The objective of this work was to develop a multicommutated flow system for the determination of $\mathrm{Al}(\mathrm{III})$ in crystallized fruits. In these samples, the addition of aluminum sulfate is permitted up to concentrations of $300 \mathrm{mg} \mathrm{kg}^{-1}$ (17) expressed as aluminum. The manifold was designed to perform an in-line dilution strategy based on the zone sampling approach that allows the adaptation of the same manifold to a wide determination range of the analyte $(0.5-100 \mathrm{ppm})$ without the necessity of manually changing the manifold configuration.

In the zone sampling process, a selected part of a dispersed sample is resampled and introduced into another carrier stream for further processing. This approach was conceived (18) in FIA to provide high degrees of sample dispersion in an efficient and controlled way. The control of the dispersion is based on the time and the period of the resampling.

\section{MATERIALS AND METHODS}

Solutions. All chemicals were analytical grade, and boiled (degassed) MilliQ water was used throughout the work. The $0.5 \mathrm{M}$ buffer carrier solution was prepared daily by diluting $1: 2$ a $1.0 \mathrm{M}$ hexamethylentetramine (Fluka 52709) (hexamine) solution and adding 2.0\% (w/v) ascorbic acid (Merck, 1.00127), followed by the adjustment of the $\mathrm{pH}$ of the solution to 5.0. Aqueous stock CAS (Sigma C-1018) solution of $0.1 \%(\mathrm{w} / \mathrm{v})$ was prepared and diluted as necessary.

The working standard solutions of aluminum and iron were prepared by rigorous dilution of the stock standard solutions of $1000 \mathrm{mg} \mathrm{L}^{-1}$ Spectrosol 14031 and Spectrosol 141404A, respectively. For the dispersion studies, a bromothimol blue solution was prepared as described by Ruzicka and Hansen (19).

Sample Treatment. The samples of crystallized fruits (cherries, figs, turnips, and oranges) were purchased at local supermarkets. Five to ten grams of fruit samples was dried and ashed at $550{ }^{\circ} \mathrm{C}$. The ashes were recovered in $5 \mathrm{~mL}$ of $\mathrm{cc} \mathrm{HCl}$ and in $2 \mathrm{~mL}$ of $\mathrm{cc} \mathrm{HNO}_{3}$, followed by diluting in hot water and filtering; the final volume of the filtrate was $100 \mathrm{~mL}$. These solutions were either introduced in the multicommutated system or were analyzed by the reference atomic absorption procedure (20)

Apparatus. The flow set up consisted of an UV/vis spectrophotometer (Unicam 8625 Cambridge, England), equipped with a flow cell (Hellma 178.710 QS, Mullheim/Baden, Germany) with an internal volume of $80 \mu \mathrm{L}$. A Crison MicroBu 2031 (Crison Instruments, Alella, Barcelona, Spain) automatic buret equipped with a $5 \mathrm{~mL}$ syringe (Crison 9225) was used to propel the solutions by aspiration. The manifold was built by using three way solenoid valves (NResearch 161T031, Cardwell, NJ), PTFE tubing with $0.8 \mathrm{~mm}$ i.d., T-shaped confluences made of Perspex, and homemade fittings. One of the channels of valves $\mathrm{V}_{1}, \mathrm{~V}_{2}$, and $\mathrm{V}_{3}$ (Figure 1A) was closed. A homemade power drive based on a UNL 2003 integrated circuit was used to operate the solenoid valves (10). The analytical system control was achieved by means of an interface card (Advantech model PCL-818L, Taipei, Taiwan) and a 486 microcomputer. The software was developed in QuickBasic (Microsoft) and enabled the control of the solenoid valve position and the operation of the automatic buret.

Flow Manifold and Procedure. The flow system (Figure 1A) was designed with five solenoid valves; $\mathrm{V}_{1}, \mathrm{~V}_{2}$, and $\mathrm{V}_{3}$ were responsible for the introduction of the carrier, sample, and reagent solutions, respectively, while $V_{4}$ and $V_{5}$ were used for the zone sampling process.

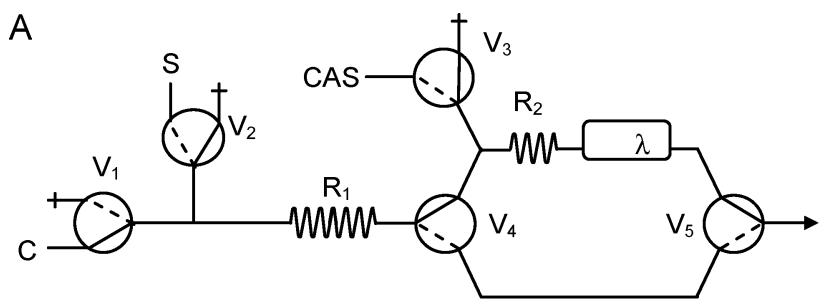

B
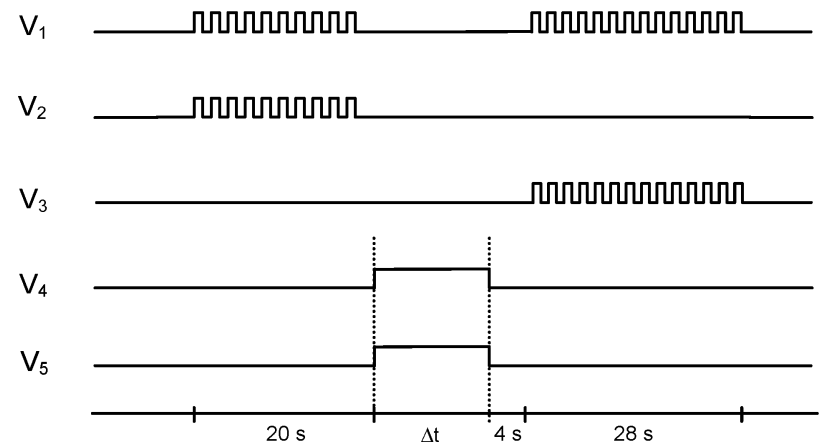

Figure 1. (A) Manifold of the multicommutated system for the determination of aluminum (III); C, carrier hexamine buffer, $0.5 \mathrm{M}, 2.0 \%(\mathrm{~m} / \mathrm{v})$ ascorbic acid, pH 5.0; S, samples or working standard solutions; CAS, $0.03 \%(\mathrm{~m} / \mathrm{v})$ CAS solution; $\mathrm{V}_{1}-\mathrm{V}_{5}$, three way solenoid valves; $\mathrm{R}$, reactor; $\mathrm{R}_{1}, 100 \mathrm{~cm} ; \mathrm{R}_{2}, 50 \mathrm{~cm} ; \lambda$, spectrophotometer, $545 \mathrm{~nm} ; \boldsymbol{\Delta}$ indicates the position of the syringe pump used to aspirate the solutions. (B) Timing course of the solenoid valves; $\Delta t$ delay time.

The carrier solution, containing a hexamine buffer and ascorbic acid, was inserted through $\mathrm{V}_{1}$ valve and was used to establish the baseline. The sample or standard solutions were not introduced as a whole volume but in a binary sampling mode: small volumes of sample and small volumes of the carrier solution were sequentially introduced by alternating the switching on and off of the respective valves. The flow rate and the time programming (Figure 1B) of $\mathrm{V}_{1}$ and $\mathrm{V}_{2}$ valves determined the volume of each slug to be introduced and also the total sample volume. The formed sample string was aspirated through the $\mathrm{R}_{1}$ reactor where dispersion of the sample zone and the reduction of $\mathrm{Fe}$ (III) to $\mathrm{Fe}$ (II) by the ascorbic acid occurred for the elimination of the $\mathrm{Fe}(\mathrm{III})$ interference. $\mathrm{V}_{4}$ and $\mathrm{V}_{5}$ were operated in a synchronized fashion, and the timing of the operation determined the portion of the sample zone to be directed to the reagent addition point and later to the detector's flow cell. When these valves were on, the flow was directed through the bypass directly to the syringe pump. When these valves were switched off again, the remainder of the sample zone still kept in R1 (Figure 1A) was aspirated to the second confluence point where the reagent (CAS) was added, also in a binary sampling mode, using the $V_{3}$ valve. The operation of the $V_{3}$ valve was adjusted to the timing of the $\mathrm{V}_{4}$ valve to be able to start the addition of the reagent slugs to the sample zone when it is passing through the confluence point. Following the reagent addition, the valves were all switched off and the flow passed through the detector where the change in absorbance was monitored at $545 \mathrm{~nm}$. The timing course of the valves is demonstrated on Figure 1B.

Reference Method. The accuracy of the developed procedure was evaluated by comparison of the results obtained in the analysis of the samples by an atomic absorption spectrophotometric method using a $\mathrm{N}_{2} \mathrm{O} / \mathrm{C}_{2} \mathrm{H}_{2}$ flame atomization process (20).

\section{RESULTS AND DISCUSSION}

Optimization of the Manifold. As a first approach, the MC system (Figure 1A) was set up to study the chemical and physical conditions of the reaction and the MC process. Working conditions are represented on Figure 1. This approach, without zone sampling, was used during the optimization process. 


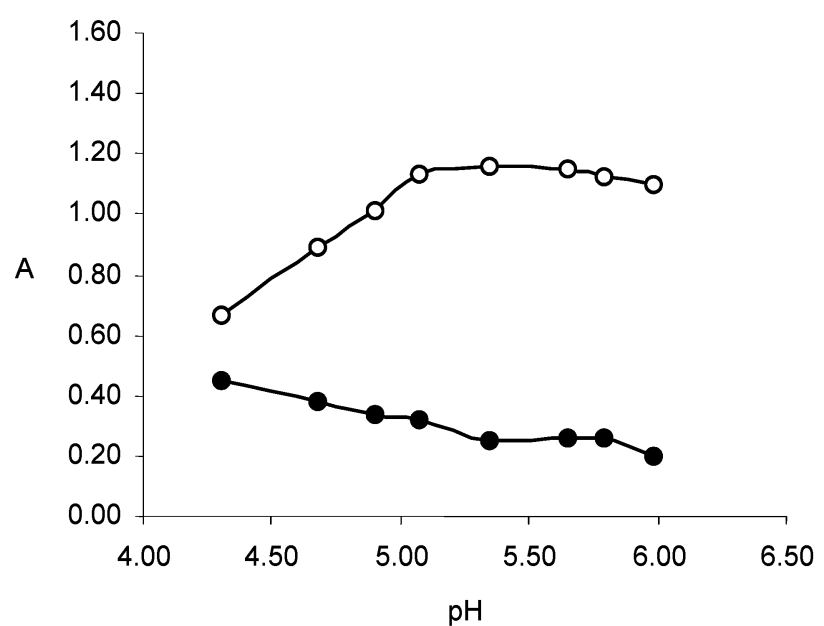

Figure 2. Effect of working $\mathrm{pH}$ on the analytical signal for the blank (0) and for the $5.0 \mathrm{ppm}(\mathrm{O}) \mathrm{Al}(\mathrm{III})$ solution. Other conditions are presented in Figure $1 \mathrm{~A}$.

The total volume of the injected sample was set at $100 \mu \mathrm{L}$ to provide a primary sample zone with an enhanced dispersion, so that it was possible to select zones of higher dispersion with sufficient repeatability (18). To improve the mixing of the injected sample with the carrier buffer stream, a binary sampling approach was used. Reproducibility of the binary sampling process depends on the flow rate and on the timing course of the solenoid valves (10). Flow rates applied in multicommutated systems based on the aspiration of the solutions are relatively low (typically under $2 \mathrm{~mL} \mathrm{~min}^{-1}$ ) to avoid the formation of air bubbles inside the manifold. The limiting time interval for solenoid valves for reproducible sampling is generally considered to be $0.1 \mathrm{~s}(10)$. Using a low flow rate also means that the low volumes can be sampled with high accuracy. The combination of a flow rate of $0.6 \mathrm{~mL} \mathrm{~min}-1$ and an on-off time of $1 \mathrm{~s}$ resulted in the introduction of sample slugs with $10 \mu \mathrm{L}$ volume. Under these conditions, the repeatability of the sampling process was assessed by injecting the CAS $[0.03 \%(\mathrm{~m} / \mathrm{v})]$ solution into the buffer carrier stream. The relative standard deviation of 10 consecutive injection of the reagent solution was $0.2 \%$. During the stand-by phase, the flow rate was increased to $0.8 \mathrm{~mL} \mathrm{~min}^{-1}$ to improve the sampling frequency of the system.

The reaction rate was dependent on the working $\mathrm{pH}$ showing an increasing tendency until $\mathrm{pH}$ 5.0; over that $\mathrm{pH}$, the sensitivity stabilized (Figure 2). Additionally, it was necessary to choose a working $\mathrm{pH}$ that ensures the sufficient stability of ascorbic acid; therefore, the $\mathrm{pH}$ of 5.0 was maintained for further experiments. Acetate and hexamine buffers at same concentrations were tested, and the hexamine buffer showed higher sensitivity, in agreement with the literature findings $(16,21)$; therefore, this buffer was applied in further experiments.

The sensitivity also increased with the concentration of the reagent. This effect was studied in the range of $0.005-0.05 \%$ $(\mathrm{m} / \mathrm{v})$ CAS (Figure 3). However, increasing the concentration of the reagent also increased the blank reading; although sensitivity did not remarkably increase $(13 \%)$ over $0.01 \%$ CAS, a $0.03 \%(\mathrm{~m} / \mathrm{v})$ reagent concentration was chosen to ensure sufficient sensitivity.

The number of reagent slugs (10 $\mu \mathrm{L}$ each) added was increased up to 30 , and the effect of the reagent volume on the blank reading and on the 5 ppm signal was studied (Figure 4). The difference between the signals increased up to 14 reagent slugs $(140 \mu \mathrm{L})$ and then approached stabilization. Considering that higher values did not cause a significant increase in the

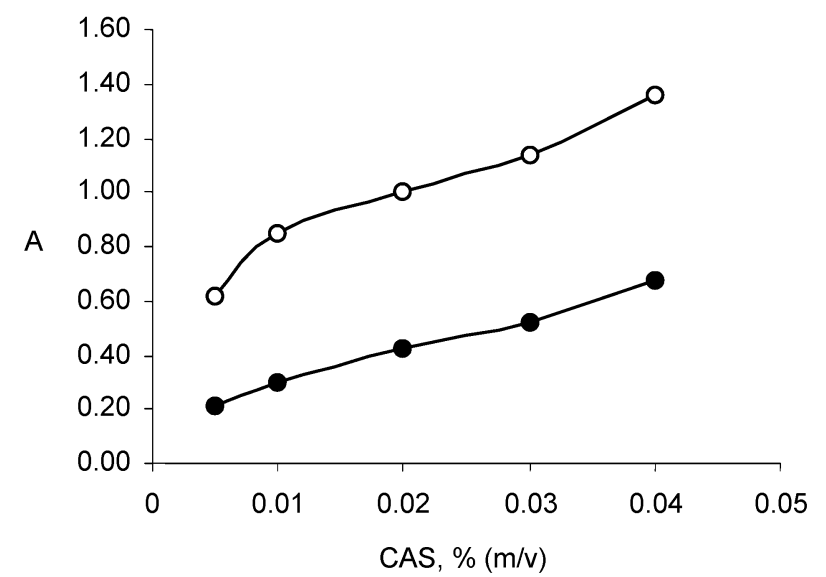

Figure 3. Effect of CAS concentration on the absorbance signal for the blank (O) and for the $5.0 \mathrm{ppm}(\mathrm{O}) \mathrm{Al}(\mathrm{III})$ solution. Other conditions are the same as presented in Figure $1 \mathrm{~A}$ except $0.5 \mathrm{M}$ hexamine buffer at $\mathrm{pH} 5.0$.

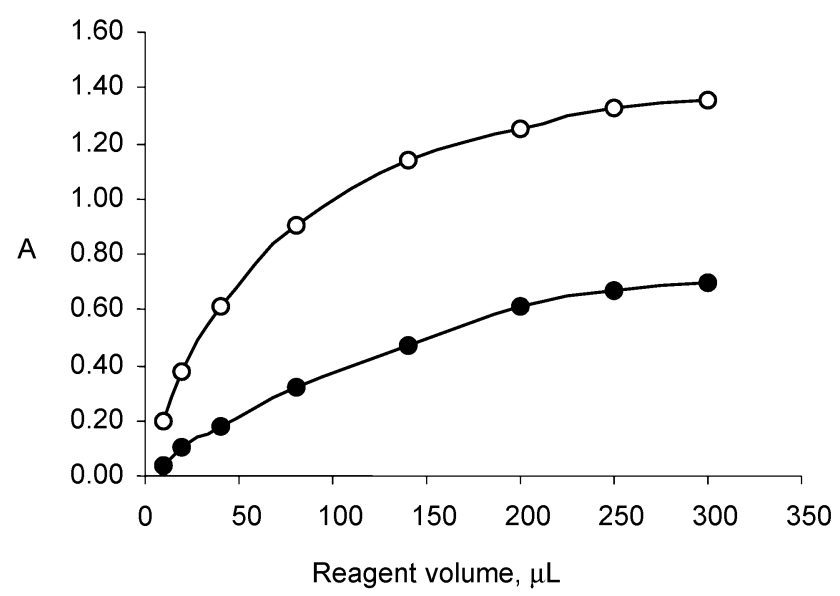

Figure 4. Effect of the volume of the reagent added on the blank ( and for the $5.0 \mathrm{ppm}(\mathrm{O}) \mathrm{Al}(\mathrm{III})$ solution. Other conditions are the same as presented in Figure $1 \mathrm{~A}$ except $0.5 \mathrm{M}$ hexamine buffer at $\mathrm{pH}$ 5.0.

sensitivity, the volume of $140 \mu \mathrm{L}$ was selected for the subsequent experiments.

Implementation of the Zone Sampling Process. Samples containing aluminum at concentrations values higher than $5 \mathrm{ppm}$ were expected to be found (17), which will then demand an in-line dilution prior to detection. For this purpose, the zone sampling approach was adapted. A part of the tail of the dispersed sample zone was selected by the timing course of $V_{4}$ and $\mathrm{V}_{5}$. The time period that these valves were on $(\Delta t)$ determined the section of the initially inserted sample zone that was sent to waste and the portion that was redirected for further processing within the manifold.

The D of the developed system was determined as recommended by Ruzicka and Hansen (19). On the basis of the dispersion studies, two additional working zones were defined. One intermediate for concentrations between 5 and $25 \mathrm{ppm}$, using a $\Delta t$ of $50 \mathrm{~s}$, and another zone for higher concentrations $(10-100 \mathrm{ppm})$ applying a $\Delta t$ of $70 \mathrm{~s}$.

Characterization of the Developed System. After system optimization, three separate zones of application were established. The figures of merit of each application zones are summarized in Table 1. Repeatability of the system was assessed by calculating the relative standard deviations for the 10 consecutive injection of sample extract and showed values under $2.4 \%$ in all of the three application zones. 
Table 1. Figures of Merit of the Developed System

\begin{tabular}{|c|c|c|c|c|c|c|}
\hline \multirow{2}{*}{$\begin{array}{l}\text { application } \\
\text { zone (ppm) }\end{array}$} & \multicolumn{2}{|c|}{ calibration $^{a}$} & \multirow{2}{*}{$\begin{array}{l}\text { LOD } \\
\text { (ppm) }\end{array}$} & \multirow{2}{*}{$\begin{array}{l}\mathrm{LOQ} \\
\text { (ppm) }\end{array}$} & \multirow{2}{*}{$\begin{array}{c}\text { SR } \\
\left(h^{-1}\right)\end{array}$} & \multirow[b]{2}{*}{ D } \\
\hline & a & $b$ & & & & \\
\hline & $0.420( \pm$ & 0162 & 0.07 & 0.23 & 32 & 5.3 \\
\hline & & $0.033( \pm 0$. & 0.61 & 2.0 & 28 & 20.5 \\
\hline $10-100$ & $0.424( \pm 0.010)$ & $0.009( \pm 0.002)$ & 0.83 & 2.8 & 24 & 223 \\
\hline
\end{tabular}

${ }^{a}$ Mean and standard deviation of calibration curve parameters from three different working days; $a$ and $b$ are the intercept and slope of the calibration curve, respectively; LOD, limit of detection; LOQ, limit of quantification (22); SR, sampling rate; $\mathrm{D}$, dispersion factor.

Table 2. Comparison of the Results Obtained for the Analysis of Crystallized Fruit Samples by the Developed Multicommutated Flow Procedure and by the Reference Atomic Absorption Sectrophotometric Method

\begin{tabular}{|c|c|c|c|}
\hline sample & $\begin{array}{c}\text { reference } \\
\text { method } \\
(\mathrm{AAS})^{a}(\mathrm{ppm})\end{array}$ & $\begin{array}{l}\text { developed } \\
\text { method } \\
(\mathrm{MC})^{a}(\mathrm{ppm})\end{array}$ & $\begin{array}{c}\text { relative } \\
\text { deviation } \\
\text { (RD) (\%) }\end{array}$ \\
\hline fruit mix & $0.9 \pm 0.1$ & $1.0 \pm 0.0$ & 5.6 \\
\hline fruit mix & $1.2 \pm 0.1$ & $1.2 \pm 0.1$ & -4.2 \\
\hline fig & $3.8 \pm 0.1$ & $3.6 \pm 0.1$ & -6.1 \\
\hline orange peel & $2.2 \pm 0.1$ & $2.3 \pm 0.1$ & 6.4 \\
\hline turnip & $1.7 \pm 0.0$ & $1.6 \pm 0.1$ & -4.7 \\
\hline turnip & $1.5 \pm 0.1$ & $1.4 \pm 0.1$ & -5.3 \\
\hline fig & $7.3 \pm 0.2$ & $7.2 \pm 0.1$ & -1.0 \\
\hline cherry & $8.3 \pm 0.2$ & $8.9 \pm 0.1$ & 6.7 \\
\hline cherry $^{b}$ & $14.0 \pm 0.3$ & $14.4 \pm 0.4$ & 2.9 \\
\hline turnip ${ }^{b}$ & $22.4 \pm 0.4$ & $21.1 \pm 0.5$ & -5.8 \\
\hline pearb & $28.7 \pm 0.4$ & $29.2 \pm 0.6$ & 1.7 \\
\hline pear $^{b}$ & $18.4 \pm 0.5$ & $17.9 \pm 0.4$ & -2.7 \\
\hline orange peel ${ }^{b}$ & $34.6 \pm 0.0$ & $34.0 \pm 0.9$ & -1.7 \\
\hline orange peel ${ }^{b}$ & $52.8 \pm 0.2$ & $53.8 \pm 1.9$ & 1.9 \\
\hline orange peel ${ }^{b}$ & $71.0 \pm 0.9$ & $71.9 \pm 0.6$ & 1.3 \\
\hline pearb & $56.8 \pm 0.6$ & $54.4 \pm 0.9$ & -4.2 \\
\hline pearb & $77.4 \pm 0.2$ & $76.2 \pm 0.9$ & -1.6 \\
\hline turnip $b$ & $43.9 \pm 0.8$ & $41.8 \pm 0.8$ & -4.8 \\
\hline
\end{tabular}

${ }^{a}$ Mean and standard deviation of three replicates. ${ }^{b}$ Spiked samples.

Iron(III) reacts with CAS in similar conditions as aluminum. To avoid the interfering effect, ascorbic acid was used to reduce iron(III) to iron(II). In the presence of $2 \%(\mathrm{~m} / \mathrm{v})$ ascorbic acid, $50 \mathrm{ppm}$ iron(III) did not interfere in the determination of aluminum(III) with a concentration of $5 \mathrm{ppm}$. At a concentration of $100 \mathrm{ppm}$, iron(III) interfered at $5 \%$ in the results for aluminum.

Depending on the application range, the consumption of reagents is very low: $0.042,<31$, and $<108 \mathrm{mg}$ per assay for CAS, ascorbic acid, and hexamine, respectively. The total waste generated was lower than $48 \mathrm{~mL} \mathrm{~h}^{-1}$, which corresponds to less than $2 \mathrm{~mL}$ per assay.

Analysis of Sample Extracts. To validate the proposed methodology, the developed procedure was applied to the determination of aluminum in crystallized fruit sample digests and in spiked samples. Spiking the samples was necessary as no real samples were found with concentrations of aluminum close to the legal limit. The procedure was carried out without any previous adjustment of the sample $\mathrm{pH}$. The results obtained in the analysis of the samples are presented in Table 2.

A linear relationship $\left(C_{\mathrm{MC}}=C_{0}+S \times C_{\mathrm{AAS}}\right)$ was established, and the values for intercept $\left(C_{0}\right)$, slope $(S)$, and the correlation coefficient were $-0.018( \pm 0.661), 0.990( \pm 0.019)$, and 0.9994, respectively, where the values in parentheses are the limits of the $95 \%$ confidence intervals (22). These figures demonstrate a good agreement between the developed and the reference procedures.
Table 3. Results Obtained in the Recovery Study When Known Amount of Aluminum Was Added to Sample Digests

\begin{tabular}{ccr}
\hline $\begin{array}{c}\text { without addition } \\
(\mathrm{ppm})\end{array}$ & $\begin{array}{c}\text { addition } \\
(\mathrm{ppm})\end{array}$ & \multicolumn{1}{c}{$\begin{array}{c}\text { recovery } \\
(\%)^{a}\end{array}$} \\
\hline 8.9 & 25 & $106.3 \pm 3.3$ \\
& 50 & $107.0 \pm 3.1$ \\
3.8 & 10 & $104.8 \pm 1.3$ \\
& 20 & $98.9 \pm 3.2$ \\
1.2 & 10 & $102.9 \pm 2.8$ \\
& 15 & $97.4 \pm 0.2$
\end{tabular}

${ }^{a}$ Mean and standard deviation of three replicates.

Recovery studies were also carried out to assess the accuracy of the developed method. Three samples with low aluminum concentration were spiked with known amounts of aluminum. The obtained results are summarized in Table 3 . These results also demonstrate the accuracy of the method, as recovery percentages were not different from $100 \%$ at a $95 \%$ confidence, the calculated $t=1.78$ was lower than the critical $t$ value ( $p=$ $0.05, n=6$ ) of 2.57 .

\section{ABBREVIATIONS USED}

CAS, chrome azurol S; MC, multicommutation; SIA, sequential injection analysis; FIA, flow injection analysis; D, dispersion number.

\section{ACKNOWLEDGMENT}

The help of Carlos Ferreira (DRAEDM) in carrying out the reference measurements is gratefully acknowledged.

\section{LITERATURE CITED}

(1) Rogers, M. A. M.; Simon, D. G. A preliminary study of dietary aluminium intake and risk of Alzheimer's disease. Age Aging 1999, 28, 205-209.

(2) WHO. Guidelines for drinking water quality. http://www.who.int/ water_sanitation_health/GDWQ/Chemicals/aluminiumfull.html. 2002/07/09.

(3) Brach-Papa, C.; Coulomb, B.; Boudenne, J. L.; Cerda, V.; Theraulaz, F. Sectrofluorimetric determination of aluminum in drinking waters by sequential injection analysis. Anal. Chim. Acta 2002, 457, 311-318.

(4) Armas, G.; Miró, M.; Cladera, A.; Estela, J. M.; Cerdá, V. Timebased mulisyringe flow injection system for the spectrofluorimetric determination of aluminium. Anal. Chim. Acta 2002, 455, $149-157$

(5) Armas, G.; Torres, J. R.; Cladera, A.; Estela, J. M.; Cerdá, V. Fluorimetric sequential injection analysis of aluminium in a micellar medium. Quím. Anal. 2002, 20, 211-215.

(6) Hawke, D. J.; Powell, H. K. J. Flow injection analysis applied to the kinetic determination of reactive (toxic) aluminium comparison of cromophores. Anal. Chim. Acta 1994, 299, 257268.

(7) Pakalns, P. Spectrophotometric determination of aluminium with Chrome Azurol S. Anal. Chim. Acta 1965, 32, 57-63.

(8) Clarke, N.; Danielsson, L.-G.; Sparén, A. Analytical methodology for the determination of aluminium fractions in natural freshwaters (Technical Report). Pure Appl. Chem. 1996, 68, 15971638.

(9) Hawke, D. J.; Powell, H. K. J. Equilibrium modelling of interferences in the visible spectrophotometric determination of aluminium(III): comparison of the cromophores chrome azurol $\mathrm{S}$, eriochrome cyanine $\mathrm{R}$ and pyrocatechol violet, and stability constants for eriochrome cyanineR-aluminium complexes. Anal. Chim. Acta 1996, 319, 305-314. 
(10) Reis, B. F.; Giné, M. F.; Zagatto, E. A. G.; Lima, J. L. F. C.; Lapa, R. A. Multicommutation in flow analysis. Part 1. Binary sampling: concepts, instrumentation and spectrophotometric determination of iron in plant digests. Anal. Chim. Acta 1994, 293, 129-138.

(11) Ruzicka, J.; Marshall, G. D. Sequential injection: a new concept for chemical sensors, process analysis and laboratory assays. Anal. Chim. Acta 1990, 237, 329-343.

(12) Icardo, M. C.; Mateo, J. V. G.; Calatayud, J. M. Multicommutation as a powerful new analytical tool. Trends Anal. Chem. 2002, 21 (5), 366-378.

(13) Rocha, F. R. P.; Nobrega, J. A.; Fatibello, O. Flow analysis strategies to greener analytical chemistry. An overview. Green Chem. 2001, 3 (5), 216-220.

(14) Rocha, F. R. P.; Reis, B. F.; Zagatto, E. A. G.; Lima, J. L. F. C.; Lapa, R. A. S.; Santos, J. L. M. Multicommutation in flow analysis: concepts, applications and trends. Anal. Chim. Acta 2002, 468, 119-131.

(15) Ruzicka, J.; Hansen, E. H. Flow injection analysis. Part I. A new concept of fast and continuous flow analysis. Anal. Chim. Acta 1975, 78, 145-157.

(16) Kronka, E. A. M.; Reis, B. F. Spectrophotometric determination of iron and aluminium in plant digests employing binary sampling in flow analysis. Quim. Anal. 1998, 17 (1), 15-20.
(17) Ministérios da Agricultura, da Saúde, do Ambiente e Recursos Naturais e do Mar; Portaria No. 646/93; Aditivos Admissíveis: Lisboa, 1993; p 3691.

(18) Reis, B. F.; Jacinto, O. A.; Mortatti, J.; Krug, F. J.; Zagatto, E. A. G.; Bergamin $\mathrm{F}^{\circ}$, H.; Pessenda, L. C. R. Zone-sampling processes in flow injection analysis. Anal. Chim. Acta 1981, 123, $221-228$

(19) Ruzicka, J.; Hansen, E. H. In Flow Injection Analysis, 2nd ed.; John Wiley: New York, 1988; p 301.

(20) Association of Official Analytical Chemists (AOAC). Official Methods of Analysis, 16th ed.; AOAC: Geithersburg, 1997.

(21) Kennedy, J. A.; Powell, H. K. J. Colorimetric determination of aluminium(III) with chrome azurol $\mathrm{S}$ and the reactivity of hydrolyzed aluminium species. Anal. Chim. Acta 1986, 184, 329-333.

(22) Miller, J. C.; Miller J. N. In Statistics for Analytical Chemistry, 3rd ed.; Ellis Horwood: New York, 1993; pp 120-124.

Received for review February 3, 2004. Revised manuscript received February 23, 2004. Accepted February 24, 2004. We thank the IFADAP for financial support through Project AGRO 273. I.V.T. is grateful to the Fundação para a Ciência e a Tecnologia for Grant SFRH/BPD/5631/2001.

JF049812V 